\title{
Critical Introductory Notes on Farming Systems Research in Developing Third World Agriculture
}

\author{
Roland Brouwer ${ }^{1}$ and Kees Jansen ${ }^{1}$
}

Received February 15, 1989; revised August 10, 1989

In Third World agricultural research of household-managed production units, the systems approach is applied in the form of Farming Systems Research (FSR). Several authors reviewed here have criticized the way in which this is done. It appears that most of them neglect the fact that most FSR belongs to the "hard" systems approach. The problem context (the household production unit and its surrounding socioeconomic system), however, consists of sense-giving subjects, which have conflicting goals and interests. Their thinking and behavior are determined largely by power relations. Therefore, in FSR, the hard systems approach should be discarded and a critical alternative approach should be developed instead.

KEY WORDS: agriculture; Third World; farming systems research; critical systems thinking.

\section{INTRODUCTION}

At this moment, the breakthrough of an "integrated" and "holistic" approach in agricultural science is one of the most interesting developments in this field. Agricultural scientists of various disciplines try to integrate their disciplinary views into one, holistic analysis, which is based on systems theory. Since the end of the seventies, they seem to have had success, as the International Agricultural Research Centers (IARCs) are promoting a more holistic approach to the problems of agriculture in the

\footnotetext{
${ }^{1}$ Studium Generale, Gen. Foulkesweg 1, 6703 CP Wageningen, The Netherlands.
} 
Third World. ${ }^{2}$ In the sixties and seventies, these institutions formed the R\&D system behind the Green Revolution. ${ }^{3}$ Doubt concerning the content and form of this new approach is rising; for example, Holt and Schoorl (1985) state, "The almost complete acceptance of the systems approach by agricultural professions in planning is a cause for real concern."

Integrated, holistic, and interdisciplinary approaches and systems theory all denote a transformation that is taking place within science. The fact that so many different words are used to describe this transformation indicates that we are dealing with a rather complicated matter. The most dominant research programs that try to integrate systems theory in agricultural research concentrate on Farming Systems Research (FSR). FSR is related mainly to problems in crop production, but can be found in other areas as well. We can see discussions of animal husbandry using an FSR perspective (Frankenberger, 1986). In forestry it is used in the introduction and research of agroforestry systems (cf. Jones and Price, 1987; Raintree, 1984 ) and it is also applied within the area of watershed management (Merill Sands, 1986). FSR is used and developed not only by disciplines such as biology and crop sciences, but also by sociology and economics (see Anderson, 1985). This opens the way to the integration of the special characteristics of agriculture in a peripheral economy in the research program. This article gives a short introduction to the state of the art of FSR and reviews different forms of criticism of FSR. It concludes that the problematic character of FSR, as it is actually conceived, is scarcely discerned and that a critical approach to study and to developing farming systems has hardly been developed.

\footnotetext{
${ }^{2}$ The International Agricultural Research Centers (IARCs) are International Center for Tropical Agriculture (Cali, Colombia), International Potato Center (Lima, Peru), International Maiz and Wheat Improvement Center (Mexico), International Board for Plant Genetic Resources (Rome, Italy), International Center for Agricultural Research in the Dry Areas (Syria), International Crops Research Institute for the Semi-Arid Tropics (Hyderabad, India), International Food Policy Research Institute (Washington, V.S.), International Institute of Tropical Agriculture (Ibadan, Nigeria), International Laboratory for Research on Animal Diseases (Nairobi, Kenya), International Livestock Center for Africa (Ethiopia), International Rice Research Institute (Los Banos, Philippines), International Service for National Agricultural Research (The Hague, Netherlands), and West Africa Rice Development Association (Monrovia, Liberia).

${ }^{3}$ The Green Revolution was the dominant agricultural development strategy in the 60 s and 70 s, based on the introduction of new high-yielding varieties together with an input package (fertilizers, herbicides, insecticides, etc.). Higher productivities were limited mainly to rice and wheat and to irrigated areas (principally in Asia). It has been argued that the Green Revolution has exacerbated economic inequalities in peasant communities because, for example, only a limited group of farmers could afford the additional expenses for fertilizers, chemicals, and irrigation [see, e.g., the Introduction of Anderson et al. (1982)].
} 


\section{FSR: CONCEPT AND METHOD}

Although FSR covers a broad spectrum of research and development activities, some general common concepts can be discerned. The central goal of FSR is "to increase the productivity of the farming system in the context of the entire range of private and societal goals, given the constraints and potentials of the existing farming system" (Gilbert et al., 1980; quoted by Peters, 1988). The central feature of its method is on-farm research from a farming system perspective.

A farming system perspective can be described as follows: (a) the farm as a whole is viewed in a comprehensive manner, to obtain an understanding of the interrelations of components of the system; (b) the choice of priorities for research reflects initial study of the whole farm; (c) research on a farm subsystem is legitimate FSR, provided the connections with other subsystems are taken into account; (d) evaluation of research results explicitly takes into account linkages between subsystems; and (e) as long as the concept of the whole farm and its environment is preserved, not all the factors determining the farming system need to be considered as variables-some may be treated as parameters (Norman and Collinson, 1985). FSR, by nature, cuts across conventional commodity and disciplinary boundaries; it is interdisciplinary (Merrill Sands, 1986). Another central feature of FSR is that it offers a classification of farming systems and of farmer groups, which are usually referred to as "recommendation domains."

In spite of the extensive discussions about the different stages in FSR programs, the five basic activities given by Shaner et al. (1982) are still valid: ${ }^{4}$ (a) target and research area selection and possibly a first definition of recommendation domains; (b) problem identification and development of improved technologies for the area's small farmers; (c) planning on-farm research; (d) farm research and analysis, in which the promising strategies and technologies are tested under local farmer conditions, and (e) extension of results. Sometimes an evaluation is proposed. These basic phases correspond to the methodology of more elaborated systems approaches such as systems engineering, in which the phases--systems analysis, systems design, implementation, and operation - are distinguished [see Jackson's (1985) treatment of G. M. Jenkins].

Despite the widespread use of the term FSR, substantial ambiguity persists as to its meaning. This ambiguity is reflected in a wide variety of methods. Hence, several authors have tried to develop a classification of FSR. Fresco discerns two main streams: francophone and anglophone. The

\footnotetext{
${ }^{4}$ For further discussion on the method of FSR and the different stages, see Fresco (1984), Norman and Collinson (1985), Maxwell (1986), and Pemberton (1987).
} 
francophone type appears as a "more formal, long-term and large-scale research undertaking aimed at developing the potential of a geographical region. ... Anglophone farming systems research, on the other hand, ... does not aim at a profound change of traditional agriculture, but rather at incremental changes"' (Fresco, 1986). Simmonds (1986) defines three types of FSR: FSR sensu stricto, On Farm Research/Farming Systems Perspective, and New Farming Systems Development. Contrary to the last type, the second one promotes small, stepwise changes in the farming system. FSR sensu stricto is conceived as a true systems analysis resulting in a detailed quantitative model of an existing farming system. Merrill Sands (1986) divided FSR into eight forms that differ in goals and in the extent of the integration in development schemes. Her classification shows some overlap with the other two.

It should be obvious from this short description that FSR is anything but a lucid concept.

\section{FSR AS AN ANSWER TO THE TRADITIONAL R\&D SYSTEM}

FSR is not an entirely new research approach. In the Third World already in the twenties of this century, FSR-like research was done by De Vries on Java and by de Schlippe in the Belgian Congo. Ever since, in francophone Africa, agricultural scientifists have been doing research using a farming systems perspective (Fresco, 1984, 1986). However, in most cases these studies have had a more academic character, while FSR is directly related to technology development.

In the mid-seventies it became clear that the technologies developed to bring about a Green revolution could not simply be transferred to other areas and crops. In many regions the Green Revolution failed. The IARCs had played an important role in the improvement of crops and other activities related to the Green Revolution. The Green Revolution, however, did not fulfil its expected goals. Already in 1970, a report circulated within the International Rice Research Institute (IRRI), in which the authors pointed out the unsuitability of the new technology for large numbers of cultivators (Oasa, 1985). From then on, the IARCs placed FSR-like programs on their research agendas.

The "yield gap" between research station and small farmers is being given attention. The on-farm production of the improved crops almost always appeared to be lower than the production of the fields of the research stations. Apparently, something on the farms made it impossible to achieve maximum production. It appeared that many cultivators were unable to adopt the techniques and varieties that were developed by the IARCs 
(Chambers and Ghildyal, 1985). Innovation evidently consisted not only of the invention of a new technology but also of its acceptance by the target group. It became clear that certain differences between the context within which the technology was designed and the context within which it was to be used inhibited a full adoption. Chambers and Jiggins (1987) give a clear survey of these differences. Finally, it appeared not only that the results of the Green Revolution achieved less production than in the laboratories of the IARCs and that many cultivators were unable to use them, but also that they had disastrous social and ecological effects: plagues, pests, erosion, and social inequity (Conway, 1985a, b; Oasa, 1985).

The breakthrough of FSR in the seventies must be seen as a reaction to the limitations of the Green Revolution. The necessity was expressed to establish a better understanding of the small farmers by new forms of communication and interaction. Problem identification and experiments should no longer be made exclusively within the safety of the research stations, but on the fields of the farmers as well (Chambers and Ghildyal, 1985; Ashby, 1986). This opens up the road to a new relationship between development and proliferation of new technologies. The former research organization along disciplinary lines was looked upon as inadequate to solve small farmer problems. However, the central research objective of earlier programs, an increase in production especially of marketable crops, is maintained (Norman and Collinson, 1985).

\section{FSR AS A SYSTEMS APPROACH}

In agricultural research several systems theory approaches exist. Bawden et al. present a survey in which the relations between the various approaches and the scientific disciplines are presented. Following Checkland (1984), they define two main streams: the "hard" systems approach and the "soft" systems approach. Most FSR belongs to the first stream (Bawden et al., 1985).

Besides FSR, a second hard systems approach exists in agricultural research which is based on ecology and the use of systems theory in ecology. Simulation models of specific parts of the plant production process are built (Rabbinge, 1986; Keulen and Wolf, 1986). The aim of this approach is to identify the minimum needs of a certain production system (e.g., crop system) to achieve a production that corresponds to the possibilities set by crop, climate, and reclamation level (De Wit, 1986). This approach can be characterized as a "resource-based" strategy. Attempts have also been made to develop models that describe food production and distribution with the incorporation of detailed agronomic information on a world scale (Tims and Faber, 1986; Faber, 1986). 
FSR is seen as a systems approach because its object is regarded as a system and because of the interdisciplinary way in which it strives after problem solutions. The resource-base strategy is considered a systems approach because it applies itself to building simulation models to study the behavior of systems, which are normally strictly delimitated. Although these two approaches can be regarded as two different schools we see a rapprochement at the moment (e.g., Fresco, 1986; Plucknett et al., 1987).

The concept and method of FSR refer to the systems theory. However, in many examples of actually implemented research, little appears of this theoretical background [see, for instance, research done by Jones and Price (1985)]. On the other hand, the work by Fresco (1986) is a good example of explicit linkages to systems theory.

A farming system can be defined as a "unique and reasonably stable arrangement of farming enterprises that the household manages according to well-defined practices in response to physical, biological and social-economic environments and in accordance with the household's goals, preferences and resources. These factors combine to influence output and production methods. More communality is found within the system than between the systems. The farming system is part of larger systems-e.g. the local community-and can be divided into subsystems - e.g. cropping systems" (Shaner, 1982). Fresco (1986) discerns the following subsystems (for the sake of simplicity animal production is disregarded): "At the lowest level, one finds the cell and the plant organs, followed by the plant itself. Plants combine into crops, crops into fields that may carry crop populations of various species and variety, weeds and pathogens. The farm is situated at the next higher level. Groups of farms combined into villages or land-use units. These in turn combine in regions, which may cover a part of a country, an entire country or even a group of countries."

\section{A SURVEY OF THE CRITIQUES UNTIL NOW}

In this section we present a survey of the comments made on FSR until now. These comments can be divided into two categories. The first type criticizes the way in which FSR is implemented. Its arguments are not directed against its theoretical basis, but against the implementation of FSR. We call this type internal comments. The second type is contrasted to the first one, as it does not deal with the implementation of FSR, but tries to criticize it on a meta-level. It is directed against the political-economic structures in which FSR is developed and practiced and against its theoretical foundations. We call this type external comments. In this context, the words "internal" and "external" do not refer to the relations between components 
of the system and between the system and its surroundings, but to the level of critique.

\subsection{Internal Comments on FSR}

(a) The first comment concerns the low level of methodological development of FSR. Merrill Sands (1986) calls the variation in the precision in which the concept is used one of the ambiguities of FSR. FSR has been interpreted as a framework for agricultural research but also as a strategy for rural development and by others as a specific methodology for adaptive research. The central concept of FSR, the farm system, is only loosely defined. A lot of research is labeled FSR but is not carried out in a systemic way. Although the integration of socioeconomic analysis into agricultural research was seen as a central concept of FSR, it is not uncommon that in FSR socioeconomic factors are completely ignored (Merrill Sands, 1986).

(b) The second comment concerns the extent to which attention is paid to the interests of the farmers. Chambers and Jiggins (1987) point at the lack of explicit focus on Resource-Poor Farmers. In practice, FSR priorities have been heavily influenced by the mandate of the international research institutes who have thus far focused on particular crops (Fresco, 1984). When an FSR project is started most of the objectives have already been fixed, and FSR is then an approach to organize research to achieve the objectives. Farmers' interests are neglected and not considered as a starting point for development; farmers' knowledge is used only as an input factor.

(c) Fresco also stresses the influence exercised by the scientific background of the researchers. The bias that results from this often leads to technological reductionism: "The holistic and complex picture of the farming system during the diagnostic phase is often reduced to one or a few technical constraints, for which technological solutions are to be found" (Fresco, 1984; see also Berry, 1984).

(d) Another point of criticism is that most FSR pays far too little attention to the position of women (Flora, 1983a, b; Fresco, 1986; Jiggins, 1986; Postel-Coster, 1986). The common conclusion of this kind of comment is that, in comparison with traditional agricultural research, FSR offers a better opportunity to incorporate the gender issue. A system is seen as a dynamic whole of interrelated parts. Translated to the farming system, intrahousehold relations and the division of resources, tasks, and responsibilities between sexes have to be considered as elements and relations within the system. "With a women's component added to the FSR-program, neither the methodology nor . . . the assumptions change. Indeed, nothing special has to be done for women farmers. . . " (Gladwin and Almy, 1984). Jiggins and 
Flora do not fully share this view. They say that something has to change: more women should be involved as researchers.

(e) The fifth form of criticism that leaves the method itself untouched is presented by Garrett $(1986 \mathrm{a}, \mathrm{b})$. She points out that a stratification of cultivators in homogeneous groups, for which the technology developed in FSR should be relevant and appropriate (recommendation domains), should not be made according to ecological or technological criteria, but according to socioeconomic position. The concept of the recommendation domain is used to resolve the tension between the diversity among individual farms and the desire to design technology applicable to as large a number of farms as possible. Using a diagram by Deere and De Janvry (1979), she defines three categories of cultivators: petty commodity producers, peasants, and semiproletarians. These strata differ in their relations of production, and as a consequence, this distinction implies differences in the organization of household economics, specifically competitive demands on labor time and monetarization of on-farm production. Each target group demands its special type of FSR. FSR on behalf of petty commodity producers, who rely more on hired labor and less on unremunerated family labor, should be aimed at increasing the production of crops for the market. In the case of FSR for the second group, the peasants who rely principally on family labor, she recommends FSR aimed at increasing the production for home consumption in order to increase food security. The semiproletarians, who have to hire out their labor power to survive, hardly can benefit from any form of FSR. Only marginal improvements in cropping enterprises are possible.

(f) The sixth form of criticism concerns the way in which the farming system is defined. We can discern two types of comments: (i) academic and (ii) political.

(i) FSR includes the definition of endogenous and exogenous constraints. Exogenous constraints such as government policies on input prices or agroclimatic factors are left out of FSR but, of course, do influence the farming system. Often, they determine, in combination with other factors, the endogenous constraints. The shortcoming of much FSR, that it has not adequately looked at these exogenous factors, can, according to the critics, be solved by defining wider systems (e.g., regions) according to socioeconomic factors (Little, 1985; McMillan, 1987) or according to ecological factors (Conway, 1985a, b).

(ii) In most examples of FSR, no attention is paid to power relations and inequality. The focus is limited to the introduction of technology. Hence, analysis of the influence of power relations and inequality on the development and acceptance of technology is necessary. According to these critics this does not mean that FSR 
should be abandoned. Holt and Schoorl (1985) see possibilities for incorporation of power relations as an element in systems analysis. Davidson (1987) takes a similar stand: he concludes that FSR until now has neglected competing international prerogatives within a context of both local and global stratification. As a solution he suggests including political economy in FSR.

\subsection{External Comments on FSR}

Apart from the comments made on FSR that focus on its implementation, another form of criticism exists. This is the meta-level, external criticism which concentrates on the theoretical foundations of FSR and the politicaleconomic structures in which it is developed and practiced. Such criticism comes (a) from within systems thinking itself and (b) from outside systems thinking, attacking the whole idea of the systems approach.

(a) From within systems thinking itself there are, by implication (because the authors concerned have not considered FSR specifically) two possible types of criticism: (i) from the soft systems perspective and (ii) from the critical systems perspective.

(i) Soft systems thinkers would attack the "paradigm" used within FSR. Most FSR is an example of what Churchman (1984) and Checkland (1984) call the hard systems approach. This type of systems theory is characterized by a strong positivist bias. It sees itself as an answer to Cartesian reductionism but still sets out from a mechanistic vision of the world: by changing some elements or relations, the entire system can be improved. The hard systems thinkers suppose that the world can be observed, modeled, and optimized (Checkland, 1984). The soft systems approach discards the presumption of a unique, knowable truth. Instead of this truth, it proposes that each of the subjects involved in the system has his own vision on the world, his own Weltanschauung. Problem solving within this approach no longer has the character of optimization, but of a learning process in which all participants learn to know and appreciate each other's world visions.

Checkland (1984) refers to the critique delivered by Critical Theory (mainly by its spokesman Habermas) on the systems approach. Habermas sees the systems approach as "one more example of cultural manipulation of Western society by the science-andtechnology-dominated-purposive-rational mode of thought." (We return to this point somewhat later on.) Checkland suggests that the soft systems approach and Critical Theory both take the problem of 
human action and communication seriously; both conclude that hard systems analysis, tied to technical rationality, cannot cope with the multivaried complexities of the real world; and both, denying the inevitability of separating rationality and values which characterizes natural science, try to bring the two together in rational communicative interaction. Checkland admits that one point of difference between his position and Critical Theory remains intact: the poltical stand.

(ii) From the critical systems perspective, Jackson (1982) disputes the claim made by Checkland to have answered the criticisms leveled by Habermas at the systems approach. True, soft systems thinking involves participants in a learning process in which their Weltanschauungen are identified and discussed. But Jackson, reviewing Habermas' work and applications of Checkland's method, concludes that Checkland and Churchman do not pay attention to the fact that, besides communicative competence, also discommunicative competence exists: besides the power-free discussion, we know the power-ruled discussion. "Of course, in societies characterized by great inequalities the ideologies of the more powerful are imposed on other actors who lack the means of recognizing their true interests. The results of the inequalities in power is that the existing social order, from which power is drawn, is reproduced" (Jackson, 1982). By neglecting this aspect the soft systems approach has a regulative and conservative character. It will enforce existing power differences. Jackson also raises the point that Checkland's approach does not pay attention to the historical determination of Weltanschauungen. Habermas' theory, however, is able to understand their dependence on the social structure. It provides not only a theory of communication, but also a theory of distorted communication and a theory of the kind of social structure which brings about distorted communication. This makes a fundamental difference to the paradigm in which Habermas' work should be located. This other paradigm, according to Jackson, will lead to a different political result, whereas "Checkland's methodology confines itself to working within the constraints imposed by existing social arrangements -it is regulative" (Jackson, 1982). These issues are given a further working over by Flood (1989). Jackson (1985) and Flood (1989) therefore advocate the development of critical systems theory. Systems thinking does not have to be abandoned, but it has to be based upon a critical paradigm.

(b) Other authors, however, argue that it is the systems approach itself which is to blame. They stress (i) the depoliticization that results from the 
application of the systems approach in a social context and (ii) the role FSR plays in the incorporation of farmers into the world market.

(i) Becker (1986) and Oasa (1985) acuse the systems theory thinkers of depoliticization. By formulating a systems approach that pretends to include all relevant factors and constraints, political discussion about the desirability of certain solutions is excluded: science observes, models, and optimizes; the task of politics is only to implement the scientifically proven solutions.

(ii) Oasa (1985) believes that FSR is a change in form, not in content. The methodology might have changed, but the main goals have remained the same. Oasa locates FSR in the line of Community Development and the Green Revolution. In the case of FSR, as in the case of the other strategies, the objective is not the liberation of the peasants, but conflict regulation.

FSR tries by induced technological innovation to change subsistence agriculture into a (cheap) food-producing sector. FSR affects the reproduction of the household economy by encouraging accumulation or expanded reproduction, as consequences of improvements in the means of production. In the new efforts, in the 1970s, to develop the small farm sector in developing countries, "The traditional small-farm sector would have to become the producer of agricultural surplus rather than the provider of surplus of labour, as it has been in the past" (Yudelman, 1976; our italics). The question, Who is likely to have control of the resources generated by these surpluses? is not raised. The attention which was given to small farmers was a result of the need for more food to feed the growing populations but, at the same time, entertained by the fear for drastic social changes as a result of growing peasant unrest in many countries. This fear was felt in Latin America after Cuba's revolution and in Asia after great political shifts in China and later in Vietnam [see, e.g., Anderson (1982) on Asia]. Oasa concludes, "Despite its participatory component, all that may be left is for FSR to play out its stabilizing role.... The content remains in the attempt to technologically resist a profoundly political process" (Oasa, 1985).

The same line of thought is presented by Marcotte and Swanson (1987). They conclude that FSR, because of its systems perspective, cannot pay attention to social and economic disarticulation of peripheral societies. Although their criticism hits the foundation of FSR, they still see perspectives for bringing FSR sensu stricto back in. "To the extent FSR is viewed as a development strategy independent of the prevailing political economy-any political economy -it is likely to fail. FSR is not a development strategy per se, but a 
methodology for collecting necessary agricultural information. It is the utilization of this information by the agricultural administrators which will provide for enlightened policies, and thus, development with equity" (Marcotte and Swanson, 1987).

\section{CONCLUDING REMARKS}

Until now, we have presented a survey of the discussion about FSR and systems theory. To contribute to this discussion we try to elaborate briefly on the comments made by Fresco, Garrett, Davidson, and Holt and Schoorl by radicalizing them and relating them to the critiques of Jackson, Marcotte, and Oasa.

Our comment is directed toward two levels: the level of FSR itself and the level of systems theory. At the first level we have the following seven remarks:

\subsection{What to Think of FSR}

(a) Most FSR leads toward a top-down approach. Only lip service is paid to the farmers' priorities (see also Fresco, 1984).

(b) Most FSR is hampered by a strong technological bias (Berry, 1984), although it cannot be ignored that more causal relations between material objects and functional and social human actions can be understood by means of FSR.

(c) A lot of research is implemented under the flag of FSR which does not deserve it, as it is nothing else than on-farm research, without any analysis of a system.

(d) FSR barely offers the possibility for the improvement of the socioeconomic situation of the truly marginal rural strata: the peasants and the semiproletarians. The socioeconomic analysis of the small-farmer sector is often very limited and neglects social contradictions. Sporadically different strata of farmers are distinguished; the only exception is the work of Garrett, who combines FSR with a political-economy approach (Garrett, 1985a, b). But even Garrett does not tackle the problem completely, ignoring the fact that changes in the production conditions of one stratum directly influence the economic conditions of other strata (e.g., by lower prices because of a higher agricultural production by one stratum).

(e) With FSR, the aim of agricultural research and development has not been changed. Like Community Development, the Green Revolution, and Integrated Rural Development, FSR has no other objective than to enlarge the market by developing technologies that are acceptable to those groups that, until now, have been "forgotten." Here we agree with Oasa (1985). The 
surplus that results from a higher production does not necessarily lead to an improvement in the income and well-being of the farmers.

(f) The isolation of the farming system from its social, political, and economic environment means that too many variables are regarded as parameters. Hence important possibilities and limitations for improving the living conditions of farmers (men and women) are neglected.

(g) FSR systematically disregards conflicts on household and other. levels. No attention is paid to social and economic disarticulation (see Marcotte and Swanson, 1987). When attention is paid to the position of women, it deals only with their functionality for the production system, for instance, that they are, in a lot of situations, important agricultural producers. Other aspects of women's social position are not dealt with in FSR, although they are of great importance in understanding power relations between sexes and, as a result, the household structure.

At the second level we observe the following:

\subsection{What to Think of Systems Theory?}

(a) We disagree with Oasa (1985), who regards FSR as a change in form but not in content. In our opinion, the breakthrough of FSR and systems theory has meant a change in the agricultural sciences: an opportunity is offered to replace Cartesian reductionism by an interdisciplinary approach. But together with the evolution of an interdisciplinary approach, a neoreductionism has arisen. Farming systems theory pretends to describe reality in an exact manner and thus neglects the fact that the delimitation of the system's boundaries, the selection of endogenous and exogenous variables and parameters and defining subsystems, is a subjective process. Although many advocates of hard systems/FSR theory acknowledge this, mostly in short additional notes, this does not affect their concept of systems theory. A necessary debate about the interwoven character of the political economy, science, technology, and knowledge generation has not yet really started. But in order to advance in the study of sociotechnical systems, while taking the critique seriously, this is an essential debate to carry on.

(b) Hard systems theory/FSR sets out from the assumption that systems are hierarchally related. In most approaches no space is left for opposition and conflict.

(c) Hard systems theory/FSR disregards the aspect of meaning (sense) giving. It is unable to pay attention to this aspect, as here we come into the domain of culture.

(d) Hard systems theory/FSR does not see man as a subject but reduces him to functional elements of the system. Questions about what is meaningful 
labor, or when a certain production structure is democratic or repressive, cannot be answered.

A farming system has to be regarded as a sociotechnical system, when we want to describe it in terms of systems theory. Both at the level of elements and at the level of acting, we make social reconstructions of reality. In analyzing the farming system it is a mistake to formulate completely separate theories on technical and social domains (Brouwer and Jansen, 1988). The problem context of peasant farming can be seen as coercive in different domains. Making a description, in fact an abstraction, of a farming system is partly a subjective process, in the political as well as in the sociological and technological aspects, and when executed with an "emancipatory" concern, a critical approach for this kind of study has to be formulated.

Our provisional conclusion is that FSR does not offer a methodology apt to describe social action "systems." Hence, a complete acceptance of FSR and hard systems theory by progressive scientists and students should be rejected, and it will lead only to "cultural manipulation." Also, attempts such as those by Holt and Schoorl, Davidson, and Checkland to broaden systems thinking, but essentially to maintain its regulative character, should be regarded with greatest reservation, as these might lead to an advancing depolitization. The power-free discussion proposed by Checkland is admirable as an ideal, but one should never make the mistake of trying to introduce it as a basis of a scientific method in a society characterized by inequity. In such a context this is socially, economically, and politically disastrous.

A first effort at formulating a "critical" systems approach has been made by Jackson $(1985,1988)$ and Flood (1989). We think that this approach can and has to be developed for agricultural research in developing countries. The problem context in which a critical system approach becomes relevant is also extant in the object of FSR.

We have our doubts about the attempt to Marcotte and Swanson to bring FSR sensu stricto back in as an information gathering method. Notwithstanding their criticism on the context in which FSR is employed, Marcotte and Swanson state that it is important to have at one's disposal a method to gather information on the physical, agronomic, and socioeconomic characteristics of small-producer farming systems, which is essential for any agricultural development effort. It seems they consider current system approaches useful in analyzing problems in the development of small-farmer agriculture in developing countries. But as we have seen, hard system approaches, as most FSR, and even soft system approaches are, in the given problem context, regulative and reflect dominant ideologies.

The way Marcotte and Swanson bring FSR sensu stricto back in is too superficial. It is not possible to break down the interrelationship between systems methods aiming to produce knowledge and development strategies 
seeking to alleviate problems, as they in fact do. They investigate only the later in a political-economy context. They neglect, however, that gathering and interpreting the information on the reality of operative farming systems are also socially defined and related to power structures. The problem of how to use FSR in an emancipatory sense is not solved by restricting FSR to pure information gathering, with an implicitly pretended objectivity. Also, the way in which we look at reality is under discussion. The problem is especially rooted in the dominant epistemological and methodological paradigms. In formulating a critical systems approach we think it is necessary, as a first step, to analyze, from a political-economic point of view, these paradigms and formulate alternatives to them.

\section{ACKNOWLEDGMENT}

The authors wish to thank Michael Jackson for his comments on an early version of this paper.

\section{REFERENCES}

Anderson, J. R., Dillon, J. L., and Hardaker, J. B. (1985). Socioeconomic modelling of farming systems. In Remenyi, J. V. (ed.), Agricultural Systems Research for Developing Countries, ACAIR Proceedings No. 11, Hawkesbury, Australia, pp. 77-88.

Anderson, R. S., and Morrison, B. N. (1982). Introduction. In Anderson, R. S., Brass, P. R., Levy, E., and Morrison, B. H. (eds.), Science, Politics, and the Agricultural Revolution in Asia, Westview Press, Boulder, Colo., pp. 1-13.

Ashby, J. A. (1986). Methodology for the participation of small farmers in the design of on-farm trials. Agr. Admin. 22, 1-19.

Bawden, R. J., Ison, R. L., Macadam, R. D., Packham, R. G., and Valentine, I. (1985). A research paradigm for systems agriculture. In Remenyi, J. V. (ed.), Agricultural Research for Developing Countries, ACAIR Proceedings No. 11, Hawkesbury, Australia, pp. 31-41.

Becker, E. (1986). Ecologie en Systeemdenken. Revoluon 11, 25-39.

Berry, S. S. (1984). The food crisis and agrarian change in Africa: A review essay. Afric. Stud. Rev. 27, 59-112.

Brouwer, R., and Jansen, K. (1988). Systems Age(d): FSR, Analyse en Kritiek, M.Sc. thesis Department of Rural Sociology of the Tropics and Subtropics, Agricultural University, Wageningen, The Netherlands (unpublished).

Chambers, R., and Ghildyal, B. P. (1985). Agricultural research for resource poor farmers: the farmer-first-and-last model. Agr. Admin. 20, 1-30.

Chambers, R., and Jiggins, J. (1987). Agricultural research for resource poor farmers. Agr. Admin. Extens. 27, 35-52, 109-128.

Checkland, P. (1984). Rethinking a Systems Approach. In Tomlinson, R., and Kiss, I. (eds.), Rethinking the Process of Operational Research and Systems Analysis, Frontiers of Operational Research and Applied Systems Analysis Vol. 2, Pergamon Press, Oxford, pp. $43-65$. 
Churchman, C. W. (1984). Thought and wisdom. In Tomlinson, R., and Kiss, I. (eds.), Rethinking the Process Operational Research \& Systems Analysis, Frontiers of Operational Research and Applied Systems Analysis Vol. 2, Pergamon Press, Oxford, pp. 67-77.

Conway, G. R. (1985a). Agricultural ecology and farming systems research. In Remenyi, J. V. (ed.), Agricultural Research for Developing Countries, ACAIR Proceedings No. 11, Hawkesbury, Australia, pp. 43-59.

Conway, G. R. (1985b). Agroecosystem analysis. Agr. Admin. 20, 31-55.

Davidson, A. P. (1987). Does farming systems research have a future? Agr. Admin. Extens. 24, 69-77.

Deere, C. D., and de Janvry, A. (1979). A conceptual framework for the empirical analysis of peasants. Am. J. Agri. Econ. 61, 601-611.

de Wit, C. T. (1986). Alleen de zon gaat voor niets op. Landbouwkundig Tijdschrift 98, 23-26.

Faber, D. (1986). The use of agronomic information in the socio-economic models of the Centre of World Food Studies. In van Keulen, H., and Wolf, J. (eds.), Modelling of Agricultural Production: Weather, Soils and Crops, Pudoc, Wageningen, pp. 329-340.

Flood, R. L. (1989). Liberating systems theory: Toward critical systems thinking. Hum. Relat. 42 ,

Flora, C. B. (1983a). Farming systems research and the land-grant system: transferring assumptions elsewhere. Rural Sociol. 3, 220-228.

Flora, C. B. (1983b). Farming systems research and farm-management research: What's the difference. Rural Sociol. 3, 292-297.

Frankenberger, D. (1986). Integrating livestock into farming systems research: An example from North Kordofan Sudan. Hum. Organiz. 54, 228-238.

Fresco, L. O. (1984). Issues in farming systems research. Neth. J. Agr. Sci. 32, 253-261.

Fresco, L. O. (1986). Cassava in Shifting Cultivation. A Systems Approach to Agricultural Technology Development in Africa, KIT, Amsterdam.

Garrett, P. (1986a). Social stratification and multiple enterprises: Some implications for farming systems research. J. Rural Stud. 2, 209-220.

Garrett, P. (1986b). Viable objectives for smallholder programs: Variation by social strata. Agr. Admin. 22, 39-55.

Gladwin, C. H., and Almy, S. W. (1984). Proposal for a Women's Farming Systems Research/ Extension Project in Kenya and the USA, 1985-1987, University of Florida.

Holt, J. E., and Schoorl, D. (1985). Technological change in agriculture-The systems movement and power. Agr. Syst. 28, 69-80.

Jackson, M. C. (1982). The nature of "soft" systems thinking: The work of Churchman, Ackoff and Checkland. J. Appl. Syst. Anal. 9, 17-29.

Jackson, M. C. (1985). Social systems theory and practice: The need for a critical approach. Int. J. Gen. Syst. 10, 135-151.

Jackson, M. C. (1988). Systems methods for organizational analysis and design. Syst. Res. 5, $17-29$.

Jiggins, J. (1987). Gender-related impacts and the work of the International Agricultural Research Centers. CGIAR Study Paper No. 17, World Bank, Washington, D.C.

Jones, J. R., and Price, N. (1985). Agroforestry: An application of the farming systems approach to forestry. Hum. Organiz. 44, 322-331.

Keulen, H. van, and Wolf, J. (eds.) (1986). Modelling of Agricultural Production: Weather, Soils and Crops, Pudoc, Washington.

Little, P. D. (1985). Adding a regional perspective to farming systems research: concepts and analysis. Hum. Organiz. 44, 331-338.

Marcotte, P., and Swanson, L. E. (1987). The disarticulation of farming systems research with national agricultural systems: Bringing FSR back in. Agr. Admin. 27, 75-91. 
Maxwell, S. (1986). Farming systems research: Hitting a moving target. World Dev. 14, 65-77. McMillan, D. E. (1987). Monitoring the evolution of household economic systems over time in farming systems research. Dev. Change 18, 295-314.

Merrill Sands, D. (1986). Farming systems research: clarification of terms and concepts. Exp. Agr. 22, 87-104.

Norman, D., and Collinson, M. (1985). Farming system research in theory and practice. In Remenyi, J. V. (ed.), Agricultural Systems Research for Developing Countries, ACAIR Proceedings No. 11, Hawkesbury, Australia, pp. 16-30.

Oasa, E. K. (1985). Farming systems research: A change in form but not in content. Hum. Organiz. 44, 219-227.

Pemberton, C. A. (1987). Improving the methodological approach to farming systems research. Agr. Admin. Extens. 26, 91-100.

Peters, H. (1988). Farming systems: Nieuwe mode of doorbraak in landbouwkundig onderzoek? IMWOO 16, 3-6.

Plucknett, D. L., Dillon, J. L., and Vallaeys, G. J. (1987). Review of concepts of farming systems research: The what, why, and how. IARC proc. Workshop FSR, ICRISAT, India, 17-21 February 1986, pp. 2-9.

Postel-Coster, E. (1986). Boerinnen en boeren in de plattelandsontwikkeling: een voorbeeld van systeembenadering in Zuid-Mali. ICA Festival Paper, Leiden.

Rabbinge, R. (1986). The bridge function of crop ecology. Nether. J. Agr. Sci. 34, 239-251.

Raintree, J. B. (1984). A diagnostic approach to agroforestry design. In Wiersum, K. F. (ed.), Strategies and Designs for Afforestation, Reforestation and Tree Planting, Pudoc, Wageningen, pp. 252-273.

Shand, R. T. (1985). Session report approaches to farming systems research. In Remenmyi, J. V. (ed.), Agricultural Research for Developing Countries, ACAIR Proceedings No, 11, Hawkesbury, Australiam, pp. 89-94.

Shaner, W. W., Philipp, P. F., and Schmehl, W. R. (1982). Farming Systems Research and Development: Guidelines for Developing Countries, Westview Press, Boulder, Colo.

Simmonds, N. W. (1986). A short review of farming systems research in the tropics. Exp. Agr. 22, 1-13.

Tims, W., and Faber, D. (1986). Modelling food policies and food production. Nether. J. Agr. Sci. 34, 283-294.

Yudelman, M. (1976). The role of agriculture in integrated rural development projects: The experience of the World Bank. Sociol. Rural. 16, 308-325. 